\title{
Identification of the Sustainable Wind and Solar Potential in Urban Areas Using a GIS Methodology
}

\author{
Teresa Simões $^{1}$, Ana Estanqueiro ${ }^{1}$, Jorge Maia Alves ${ }^{2}$ \\ ${ }^{1}$ Laboratório Nacional de Energia e Geologia-LNEG, Lisboa, Portugal \\ ${ }^{2}$ Faculdade de Ciências, Universidade de Lisboa, IDL, Lisboa, Portugal \\ Email: teresa.simoes@ineti.pt, ana.estanqueiro@ineti.pt, jaalves@fc.ul.pt
}

How to cite this paper: Simões, T., Estanqueiro, A. and Alves, J.M. (2019) Identification of the Sustainable Wind and Solar Potential in Urban Areas Using a GIS Methodology. Energy and Power Engineering, 11, 398-413.

https://doi.org/10.4236/epe.2019.1112027

Received: September 11, 2019

Accepted: December 24, 2019

Published: December 27, 2019

Copyright $\odot 2019$ by author(s) and Scientific Research Publishing Inc. This work is licensed under the Creative Commons Attribution International License (CC BY 4.0).

http://creativecommons.org/licenses/by/4.0/

\begin{abstract}
In recent years the publication of new legislation in the renewables sector, namely the one related to microgeneration systems, has contributed to an increase in the installation of renewable energy systems in Portugal. Nevertheless, the investment in these systems is still high and the risk of considering sites with reduced resource constitutes a barrier to the development of this sub-sector. In the sequence of the previous work developed in the wind energy planning area, a methodology to identify the sustainable wind and solar potential in urban areas was developed, in order to reduce the pre-installation costs related to a less suitable site selection, and also to identify the real potential of the urban areas. In order to do so, a geographical information system was used and a set of tools was developed. The methodology was structured to enable its replication in other geographical locations and is sufficiently interactive to allow for the variation of the main input data. A case study in two urban environments is presented in this document to illustrate the developed methodology.
\end{abstract}

\section{Keywords}

Sustainable Potential, GIS, Microproduction of Electricity

\section{Introduction}

In the last two decades renewable energy sector has experienced a huge growth in Portugal mainly due to national incentives. As a consequence of this high growth, namely in the wind sector, most of the best sites for wind energy deployment are currently taken or reserved. This sudden growth has imposed a 
pressing on the authorities to grant the suitable permits for grid connection and highlighted the need to define clear rules for the identification and characterization of areas with high wind potential still available for this purpose. In this context, a structured and systematic classification of the wind data available, suitable for the wind resource assessment, was initiated and this enabled the development of a database of wind potential [1], and Portuguese Wind Atlases-onshore and offshore [2]. At the same time, the development of a tool for wind deployment planning based on a methodology to identify the sustainable wind potential using GIS-Geographical Information Systems [3] was initiated. In this line of work, the developed methodologies were adapted in order to be able to apply them to the domestic electricity micro generation sector using wind and solar photovoltaic $(P V)$ systems. The need to accomplish with the European directives, and with the National Plans for Renewable Energies, reinforced the need to develop methodologies for the assessments of installation of such systems. In addition, most of the European Municipalities have signed the Covenant of Mayors that includes not only actions related with energy efficiency (especially on services buildings) but also with the installation of renewable energy systems for electricity production.

Cities use a high amount of energy, requiring more than $75 \%$ of global energy production and generating about $80 \%$ of greenhouse effect gases on a global scale. It is in this context that the concept of Smart City has become of great importance in the cities way of live. According to [4], a Smart City is a technological medium-sized community, connected, sustainable, comfortable, attractive, safe, and able to manage the use of resources in the most efficient manner. The optimization of available local resources, the use of new features as well as new investments, combined with the concepts of reuse and recycling of raw materials, are the essential foundations for fully achieving the Smart City model. In this context, encouraging the use of renewable energy in a domestic scale, a structured plan for the identification of suitable sites for the development of those systems is crucial and demands the development and application of suitable tools for this purpose at an urban scale.

This paper aims to contribute to the development of a set of tools that enable the quantification of the most important renewable resources for the production of electricity in an urban environment, i.e. the wind and solar resources (for photovoltaic applications). In this context, methodologies for the identification of the renewable energy potential available in urban environments with simple and less costly tools based on geographical information systems techniques are described. The results obtained are presented through two case studies.

\section{Planning Methodologies for Urban Renewable Energy Systems Installation}

Several studies and methods were developed in the latest years for the identification of renewable potential in urban areas. Most of the research developed in this area is mainly focused on solar and wind energy systems and uses technologies 
based on geographical information systems (GIS). The planning of renewable energy systems requires a large number of analysis and uses large amounts of information that can be mapped and geo-referenced. The GIS technology is able to manage and process this information and constitutes an asset for this kind of studies.

The authors in [5], used a set of data from anemometric stations and also wind atlas data to study the wind in the city of Guelph in Canada. These authors developed an urban wind potential map and estimated the number of turbines to install in each building. In Iowa in the United States, a GIS methodology was developed to plan the installation of wind energy systems [6]. These authors developed a model that considers a large set of restrictions, including soil use, wind resource, and environmental restrictions, among other. This methodology was developed for standard wind farms, but according to its authors, it can be of great interest to extend its application to other technologies. LNEG-Laboratório Nacional de Energia e Geologia, I.P., has developed a methodology to identify the sustainable wind potential for the development of wind farm projects in Portugal [1] [7] which can also be applied to different geographies and types of environments being, therefore, a valuable planning tool.

In [8], the authors used a GIS to identify suitable sites for wind and solar systems installation aiming the production of Hydrogen. [9] identified suitable sites for the installation of $P V$ systems, using GIS as a decision-making tool to identify which renewable technology to use in a certain site or region. [10] developed a methodology to identify the most suitable technology to install in the region of Múrcia, Spain ( $P V$, Wind, Hybrid Wind- $P V$, Hybrid Wind-Diesel) [11], have developed the program GISA Sol 1.0. This program incorporates a tool for the identification of suitable sites for $P V$ installation and considers around 80 layers of information for spatial analysis. The developed methodology allows the planning of renewable energy systems and also the management of existing systems already in operation in extensive areas.

It is thus clear that GIS platforms are of outmost importance for planning purposes since they enable the management of large amounts of information, and also provide tools to handle different kinds and formats of geo-referenced layers. Using these platforms it is also possible to automatically update maps, tables and other elements, in an easier and precise way, enabling online data publication and fast results update.

\section{Methodology}

A methodology to estimate the wind and solar sustainable potential in urban environments based on simple and user-friendly GIS tools in order to facilitate its use by less experienced users in these computer technologies was developed in this work. In the next sections, the developed methodology is presented for three different types of analyses: 1) instalation of wind technology only; 2) instalation of solar technology only; 3 ) instalation of the best spacial combination of both wind and solar technologies. 


\subsection{Methodology for the Identification of the Available Renewable Energy Potential}

The methodology for the identification of the available renewable energy potential is based on the establishment of criteria, which refer to the minimum requirements for the installation of renewable energy systems in a given location, and thus guarantee an efficient performance of each system. In a general way, the main criteria used for this purpose can be classified as: Energy-Energy production and energy resource; Physical-Available installation area and proximity to grid connection; Environmental-Noninterference with protected environmental and patrimonial elements; Economic-Positive economic indicators-Levelized Cost of Energy (LCOE), Internal Rate of Return (IRR), Net Present Value (NPV), Feed-In Tariff (FIT).

In the case of urban environments, especially when the objective is to study the whole city or district, the criteria are not so comprehensive, since the main objective is to identify the suitable areas for the installation of renewable energy systems, the detailed studies being only performed in a later stage. In this sequence, the main criteria to be applied from a planning perspective are related, in a first approach, to the suitable energy resource and available area for the installation of the renewable energy systems

\subsubsection{Methodology for the Identification of the Available Wind Potential} The identification of the available wind potential is performed in two phases using mapped and geo-referenced information on the wind resource (meaning wind speed and power density) and on buildings geometries. In a first phase, this information is inserted in a GIS platform and tools are programed considering the suitable conditions for the installation of these renewable energy systems. The output of this procedure is the definition of the available areas for the installation of the wind energy systems. In a second phase, the area occupied by a small wind turbine is defined and the sustainable wind potential is then calculated according to this parameter.

For the first phase, the definition of the input conditions related to the wind resource is necessary. This is done by imposing a minimum capacity factor $\left(F_{c}\right)$ (Equation (1)) that enables the efficient operation of the wind turbines. In this sequence, minimum values for the remaining resource parameters-mean wind speed and power density-are defined. Limits between $10 \%$ and $20 \%$ are considered normal for the $F_{c}$ parameter of small wind turbines (Trust, 2008).

$$
F_{c}=N E P s / 8760 \text {. }
$$

$F_{c}$, the capacity factor, is calculated as the ratio between NEPs (the number of production hours at full capacity) and 8760 (the total number of hours in a year). Considering the mean value of the $F_{c}$ interval mentioned above-15\%-the corresponding value for NEPs is around $1300 \mathrm{~h}$ per year. Although these parameters strongly depend on the wind distribution in a certain region and on the wind turbine power curve, it can be accepted that the mean wind speed value for 
this production is in the order of $5 \mathrm{~m} / \mathrm{s}$ and the power density around $130 \mathrm{~W} / \mathrm{m}^{2}$. These input data area then reclassified in order to obtain a final map with the areas of interest for this purpose (expressions 2 and 3).

$$
\begin{gathered}
\text { If } v_{i} \geq 5.0 \mathrm{~ms}^{-1} \text {; then } v_{i, \text { rec }}=1 \text {; else } v_{i, \text { rec }}=0 \text {; } \\
\text { If } F P I_{i} \geq 130 \mathrm{Wm}^{-2} \text {; then } F P I_{i, \text { rec }}=1 \text {; else } F P I_{i \text {,rec }}=0 \text {; }
\end{gathered}
$$

In these equations $v_{i}$ represents the mean wind speed and $F P I_{i}$ is the power density, both in the corresponding grid-point $i$ of the resource map. $v_{i, \text { rec }}$ and $F P I_{i, \text { rec }}$ correspond to the same parameters after reclassification.

The reclassified resource maps are then multiplied in order to obtain the resultant grid-points that obey all the conditions imposed to each parameter (Equation (4)). This final map will enable the calculation of the available area to use in the sustainable wind potential calculation.

$$
P o t_{0,1}=v_{i, \text { rec }} \times F P I_{i, \text { rec }} .
$$

$\operatorname{Pot}_{0,1}$ corresponds to the resultant grid, populated with "0" and " 1 " (where " 0 " is not suitable and " 1 " is suitable).

After the selected areas are found, the mean suitable area to install a wind turbine must be established. This area is determined according to the wind turbine model characteristics, namely the rotor diameter and the distance between wind turbines. The minimum area occupied by each turbine, including the space to consider between them, is obtained from

$$
A_{\min }=\left(N_{1} \times D\right) \times\left(N_{2} \times D\right) ;
$$

where $A_{\min }$ represents the minimum area, $D$ the wind turbine's rotor diameter and $N_{1}$ and $N_{2}$ are the minimum number of diameters spacing each wind turbine in the crosswind and along wind directions. In this case, the minimum distance to consider between each wind turbine is 3 diameters in the crosswind direction and 8 diameters in the along wind direction which corresponds to a final area of $24 D^{2}$. The sustainable wind potential is then obtained from Equation (6),

$$
\operatorname{Pot}_{\text {sust }}=\frac{A_{\text {tot }} \times \operatorname{Pot}_{W T}}{A_{\min }}
$$

where $P o t_{\text {sust }}$ is the sustainable wind potential of the area under study (in $\mathrm{kW}$ ), $A_{t o t}$ is the total area occupied by the grid points that obey the selection conditions, and $P o t_{W T}$ is the nominal power of the wind turbine model selected for the study.

\subsubsection{Methodology for the Identification of the Available Solar Potential} The identification of the available solar potential is also based in GIS methods. The main input data is the spatial distribution of the solar potential (irradiation in $\mathrm{MWh} /\left(\mathrm{m}^{2} \cdot\right.$ year $\left.)\right)$, and as for the wind potential, the buildings geometry layer. Most of the GIS platforms already include solar radiation tools which facilitate the mapping of the solar potential without having to use other programs. This is 
the case of the proposed methodology. The main factors that influence the selection of the suitable areas and, consequently, the available solar potential, are the available solar resource and the area to install the solar photovoltaic systems.

Based on the mapping of the solar resource in a certain urban area, it is possible to establish a set of conditions that are suitable for the installation of solar systems. In this case, contrary to the wind potential case, the available area is of outmost importance since the space occupied by a solar panel is not negligible. Also the location of the solar panels depends only on the available area of the roofs or facades and on the shadowing induced by the surrounding buildings. This last factor is naturally represented by the solar radiation tool included in the GIS and used to map the solar irradiation.

The methodology consists in considering the available area of the building's rooftops and the solar irradiation values. For this last parameter, the minimum value was selected by simulating the production of a standard photovoltaic system with enough capacity to serve a residential building with 4 inhabitants. This was performed using solar GIS online database. The minimum values to consider for the selection of the suitable sites for the installation of these systems were, $1.54 \mathrm{MWh} /\left(\mathrm{m}^{2} \cdot\right.$ year) for solar irradiation, and $29 \mathrm{~m}^{2}$ for the available area (Equation (7)).

$$
\text { Pto }_{\text {sust }} \equiv \operatorname{Irr}>1.54\left[\mathrm{MWh} /\left(\mathrm{m}^{2} \cdot \text { year }\right)\right] \text { and } A_{\min / \text { roof }}>29\left[\mathrm{~m}^{2}\right]
$$

where $P$ to $_{\text {sust }}$ is the grid-point that fulfils the suitability conditions, Irr is the irradiation value at point $i$ and $A_{\min / r o o f}$ is the minimum area of the roof that can be used to install the solar systems. The total area corresponds to the area occupied by all the selected grid-points,

$$
A_{\text {tot }}=\sum_{o=1}^{N} A_{\text {poli }}
$$

where $A_{\text {poli }}$ is the area of each polygon formed by the selected points.

Still, in what concerns the available area, most rooftops are occupied with antennas, air condition equipment and other elements. Also the income irradiation is not being one hundred percent used since in this study plane rooftops and horizontal $P V$ systems are being considered. Therefore, $10 \%$ of the available area is discounted to the overall area of the buildings. The final area is then calculated by Equation (9).

$$
A_{\text {fin }}=A_{\text {tot }} \times 0.90
$$

The available solar potential is then calculated, by selecting a standard solar technology and by considering its conversion efficiency. Equation (10) was used to estimate the available solar potential for a certain urban area,

$$
P_{\text {available }}=\frac{A_{\text {fin }}}{A_{\text {tec }}} \times P_{\text {nom }}
$$

where $P_{\text {available }}$ is the available solar potential $(W), A_{t e c}$ is the area occupied by the solar panel and $P_{\text {nom }}$ is the corresponding nominal power. 


\subsubsection{Methodology for the Identification of the Available Renewable Potential $(P V+$ Wind $)$}

The determination of the joint available potential (wind $+P V$ ) is performed assuming that the usage of space can be shared by both technologies with little interference. Thus, given that the areas of interest have already been determined by applying the methods previously described, it is necessary to define the strategy to deal with the potential interference in occupation by both technologies. Based on the minimum distance required for the installation of small wind turbines, it is unlikely to install more than one, or at the most, two wind turbines, on a building rooftop, which makes it difficult to define an appropriate value for the occupation percentage in common areas. However, and considering a conservative scenario, it was decided to deduct $10 \%$ [12] also to areas obtained for wind technology in the previous procedure. The renewable capacity is then quantified for each technology. The joint potential is then calculated based on the sum of the results obtained for each technology. The total occupation share of the two technologies involves the application of the following equations for each point of the resource grids, $p_{i, \text { wind }}$ in the case of wind resource maps and $p_{i, \text { solar }}$ in the case of solar wind resource maps:

$$
\begin{gathered}
p_{i, \text { wind }}=\left\{\begin{array}{l}
1, \text { if } p_{i, \text { wind }} \in\{W\} \\
0, \text { if } p_{i, \text { wind }} \notin\{W\}
\end{array} ;\right. \\
p_{i, P V}=\left\{\begin{array}{l}
2, \text { if } p_{i, P V} \in\{S\} \\
0, \text { if } p_{i, P V} \notin\{S\}
\end{array} ;\right. \\
p_{i, P V+W}=p_{i, W}+p_{i, P V} ;
\end{gathered}
$$

where $\{W\}$ and $\{S\}$ represent the sets that include the parameters defined as minimum for the installation of wind and $P V$ systems, respectively, and $p_{i, P V+W}$ represent the final grid for the suitable areas including all the three situations; wind, solar $P V$ and Wind + solar $P V$.

Subsequently, areas are determined corresponding to the placement of each set. In common points, it is considered that the both technologies may co-exist. Assuming a conservative and planning perspective of space use, it is possible to overlay technologies. It is however noted that, in a scenario of superimposition of two technologies, there is interference related to the shading of wind turbines in photovoltaic panels ( $P V$ panels do not cause interference in the operation of wind turbines). Thus, the shadow area caused by wind turbines in photovoltaic panels is estimated, considering the worst case scenario, i.e. the shading produced on the 21st December (winter solstice), through the Equations (14) to (16), considering that the support tower of the reference wind turbine has a height of $10 \mathrm{~m}$ [13].

$$
H_{\text {Obst }}=L_{S h} \times \tan \alpha \text {; }
$$

where $H_{\text {Obst }}$ is the height of the obstacle, $L_{S h}$ is the shadow length and $\alpha$ is the solar altitude angle given by [14]:

$$
\sin \alpha=\sin L \times \sin \delta_{S}+\cos L \times \cos \delta_{S} \times \cosh _{s} ;
$$


where $\delta_{S}$ is the solar declination given by Equation (16), $L$ is the latitude and $h_{S}$ is the time solar angle (equal to $0^{\circ}$ at solar noon).

$$
\sin \delta_{S} \cong \sin 23.45^{\circ} \times \sin \left[\frac{360 \times\left(284+n_{G}\right)}{365}\right] ;
$$

where $n_{G}$ is the day of the month in the Gregorian calendar.

In the present case, the maximum length of the shadow obtained for the center west region of Portugal, which represents the country average, was $22.4 \mathrm{~m}$. The shade of the area depends on the diameter of a reference wind turbine, so that the shadow it produces shall be, in a worst case scenario, equal to the area of a rectangle with length equal to the maximum width of the shade produced by the support tower plus the rotor plane of the wind turbine.

The power per unit area related to " $n$ " wind turbine models available on the market is then determined using the mean value of the power per shadowed area (Equation (17)).

$$
\frac{P}{A_{S h}}=a \times P_{n}+b ;
$$

where $P / A_{S h}$ represents the power per unit of shadowed area, $P_{n}$ is the nominal reference power, $A_{S h}$ is the shadowed area produced by a Wind turbine, and a and $b$ are the regression coefficients that assume the values of 0.0089 and 0.1302 , respectively.

The shadowed area produced by the Wind turbines to be installed in the common area, $A_{S h W T}$, is calculated through Equation (18).

$$
A_{S h W T}=A_{S h} \times N_{W T} ;
$$

$N_{W T}$ is the number of wind turbines to install in the common area for both technologies.

In this sequence, the joint available potential is obtained according to Equation (19).

$$
P_{\text {dispE }+S}=\left[\left(\frac{\left(A_{S E} \times 0.90\right)+A_{E}}{A_{\min W T}} \times P_{n o m_{-} E}\right)+\left(\frac{\left(A_{S E}+A_{S}\right) \times 0.90}{A_{\min P V}} \times P_{\text {nom }_{-} P V}\right)-\left(P_{P V S h}\right)\right] ;
$$

where $P_{\text {dispE }+S}$ is the Wind and $P V$ available potential; $A_{S E}$ is the suitable area to install both technologies; $A_{S}$ is the suitable area for the installation of $P V$ systems; $P_{\text {nom } \_}$is the nominal power of a reference wind turbine, and $P_{P V S h}$ is the $P V$ solar potential in a shadowed area which can be calculated by Equation (20).

$$
P_{P V S h}=\frac{P_{\text {dispE }}}{A_{S E}} \times A_{S h W T} .
$$

\section{Case Study}

The presented methodology is illustrated with a case study for two urban areas in Portugal, corresponding to two administrative regions inside a municipality 
where it was possible to obtain information on buildings polygons and attributes related to building's heights. The wind and solar potential maps were calculated using a methodology developed by [15] and are used in the present work to illustrate the methodology. Figure 1 and Figure 2 represent the irradiation, wind and power density maps in the areas under study, respectively.

Several tools were developed using the ArcG is functionality Model Builder [16] in order to enable the development of an automated process in a user-friendly and interactive way, so that the input layers and threshold values can be changed according to the user's objective.

The results obtained for the two urban areas for the identification of the available wind potential, solar $P V$ potential, and wind and solar $P V$ joint potential with the developed tools are presented in Figures 3-5 and in Tables 1-3. The wind potential in the urban areas was calculated for $10 \mathrm{~m}$ above buildings height (for buildings height varying from 3 to $30 \mathrm{~m}$, approximately).

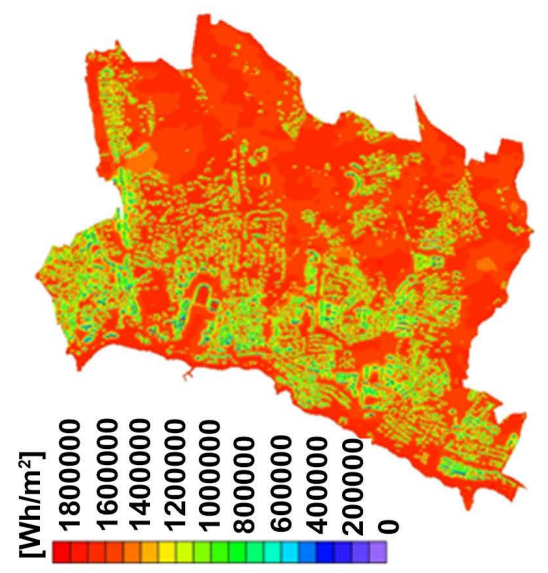

(a)

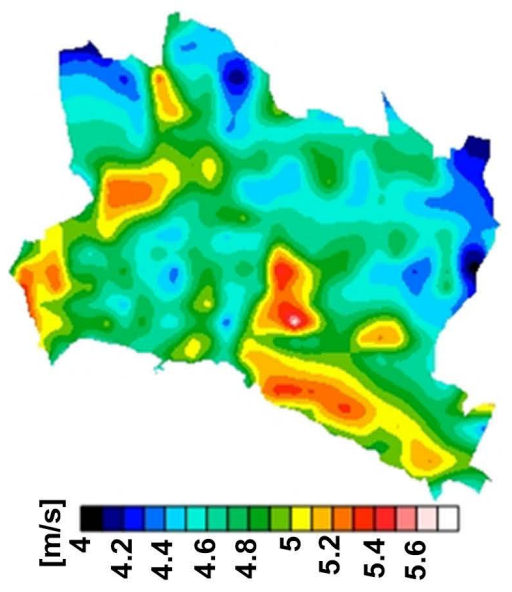

(b)

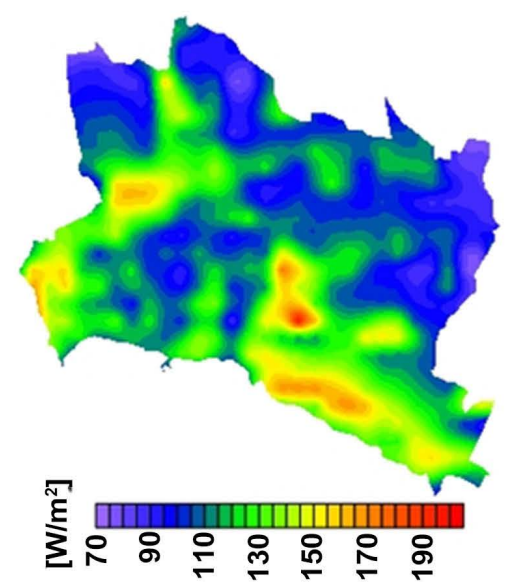

(c)

Figure 1. Spatial distribution of the (a) surface global irradiation $\left[\mathrm{Wh} / \mathrm{m}^{2}\right]$ on rooftops (b) mean wind speed $[\mathrm{m} / \mathrm{s}]$ and (c) power density for $\mathrm{h}=10 \mathrm{~m}$ above building rooftops in Estoril. 

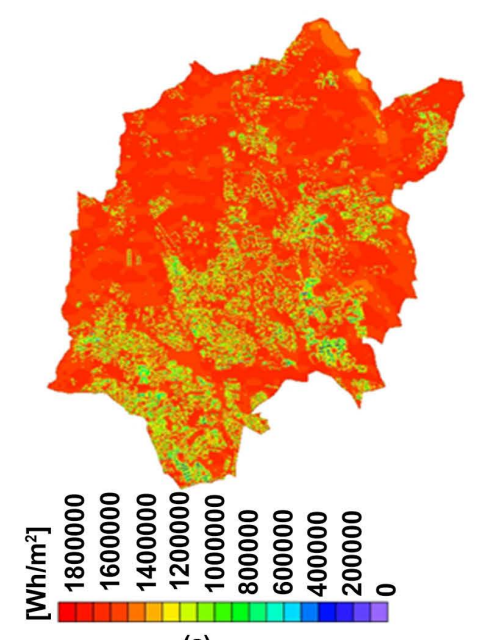

(a)

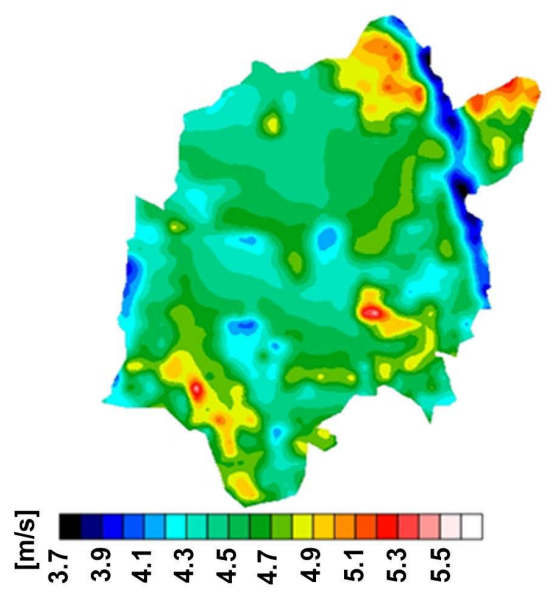

(b)

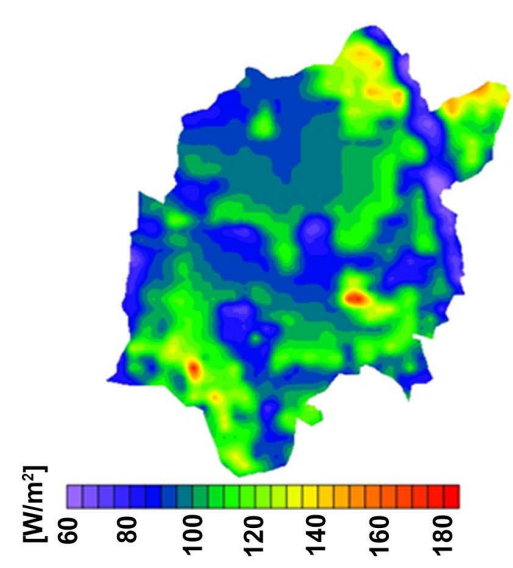

(c)

Figure 2. Spatial distribution of the (a) surface global irradiation [Wh/ $\mathrm{m}^{2} /$ year] rooftops (b) mean wind speed $[\mathrm{m} / \mathrm{s}$ ] and (c) power density for $\mathrm{h}=10 \mathrm{~m}$ above buildings rooftops in São Domingos de Rana.

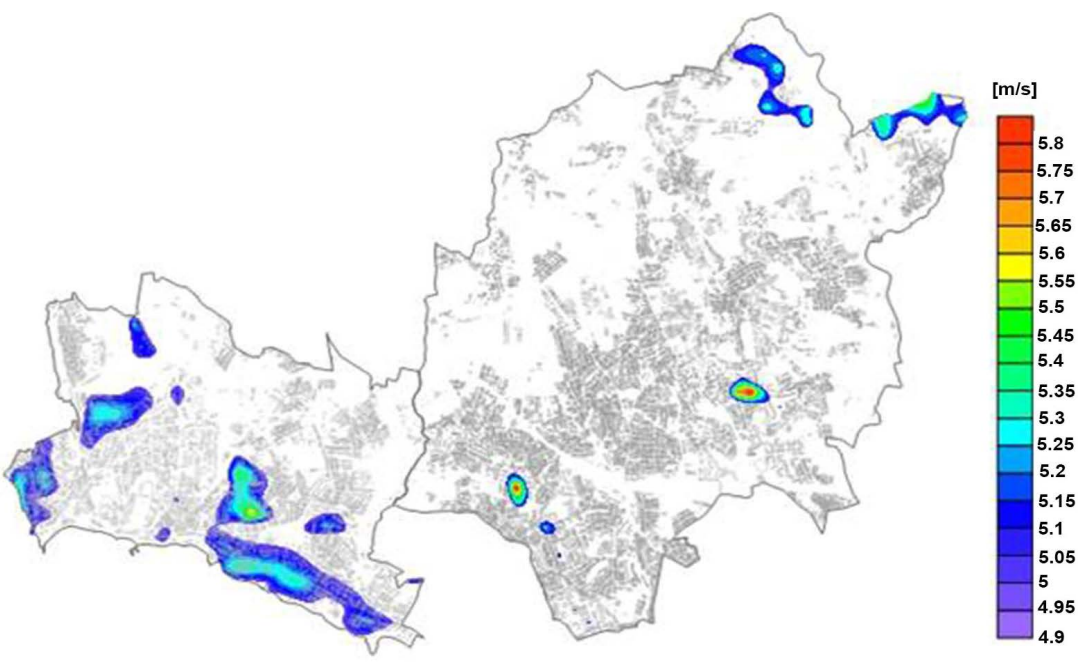

Figure 3. Results obtained with the tool developed in the GIS for wind potential illustrated with the spatial distribution of the annual mean wind speed $(\mathrm{m} / \mathrm{s})$. 


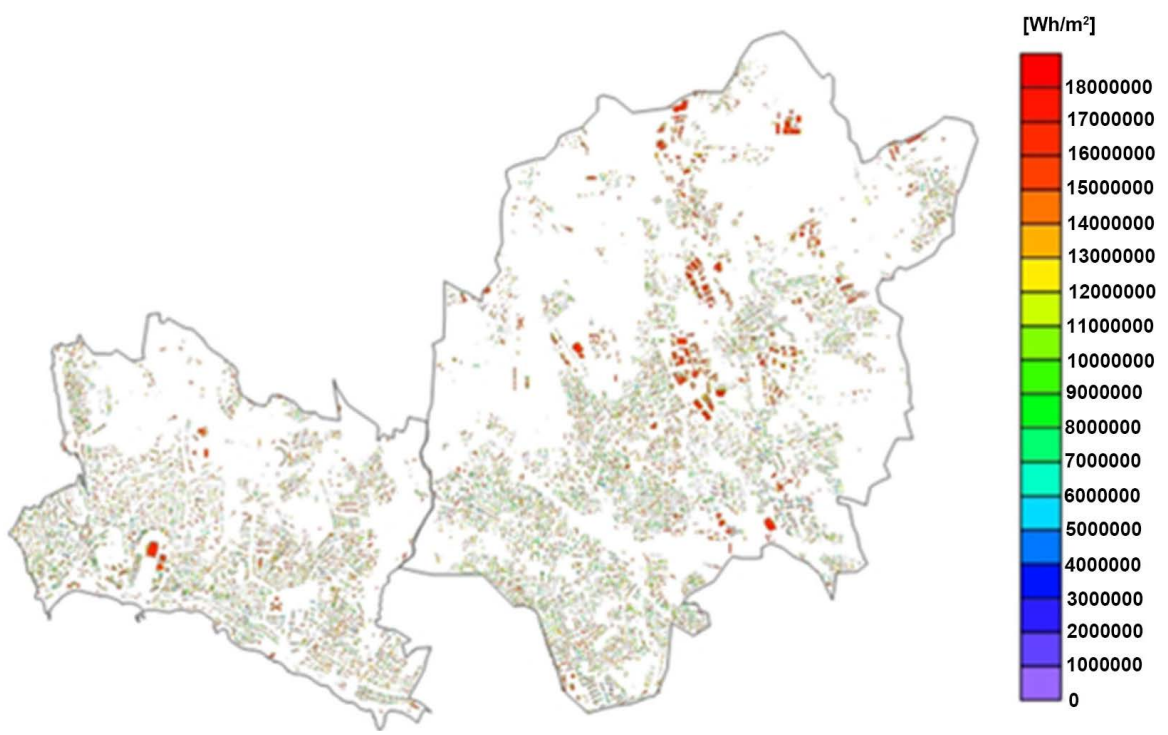

Figure 4. Results obtained with the tool developed for solar $P V$ potential represented in annual irradiation $\left(\mathrm{Wh} / \mathrm{m}^{2}\right)$.

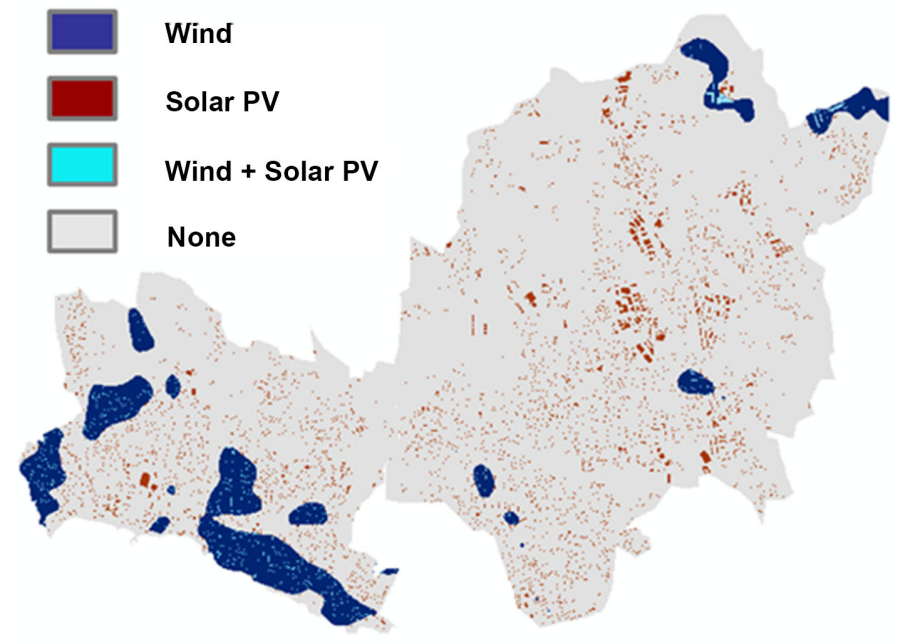

Figure 5. Results obtained with the tool developed for solar $P V$ and wind joint potential.

Table 1. Available wind potential in Estoril and São Domingos de Rana.

\begin{tabular}{cccc}
\hline Region & Total area $\left(\mathrm{m}^{2}\right)$ & Available area $\left(\mathrm{m}^{2}\right)$ & $\begin{array}{c}\text { Available wind } \\
\text { potential }(\mathrm{MW})\end{array}$ \\
\hline Estoril & $8,891,376$ & $1,607,856$ & 11.152 \\
São Domingos de Rana & $20,442,544$ & 540,544 & 3.749 \\
\hline
\end{tabular}

Table 2. Available solar $P V$ potential in Estoril and São Domingos de Rana.

\begin{tabular}{cccc}
\hline Region & Total area $\left(\mathrm{m}^{2}\right)$ & Available area $\left(\mathrm{m}^{2}\right)$ & $\begin{array}{c}\text { Available solar } P V \\
\text { potential }(\mathrm{MW})\end{array}$ \\
\hline Estoril & $8,891,376$ & 376,112 & 45.670 \\
São Domingos de Rana & $20,442,544$ & 827,280 & 100.455 \\
\hline
\end{tabular}


Table 3. Available solar $P V$ and wind potential in Estoril and São Domingos de Rana.

\begin{tabular}{cccccc}
\hline Region & $\begin{array}{c}\text { Total area } \\
\left(\mathrm{m}^{2}\right)\end{array}$ & $\begin{array}{c}\text { Available area } \\
(\text { wind }+P V) \\
\left(\mathrm{m}^{2}\right)\end{array}$ & $\begin{array}{c}\text { Available area } \\
(\text { wind })\left(\mathrm{m}^{2}\right)\end{array}$ & $\begin{array}{c}\text { Available area } \\
(P V)\left(\mathrm{m}^{2}\right)\end{array}$ & $\begin{array}{c}\text { Available } \\
\text { wind + solar } P V \\
\text { joint } \\
\text { potential }(\mathrm{MW})\end{array}$ \\
\hline $\begin{array}{c}\text { Estoril } \\
\begin{array}{c}\text { São Domingos } \\
\text { de Rana }\end{array}\end{array}$ & $8,891,376$ & 78,768 & $1,529,088$ & 297,344 & 41.247 \\
\hline
\end{tabular}

\section{Discussion of the Results}

The determination of the available and/or sustainable wind potential has been a relatively unexplored subject in recent years, therefore the methodology presented in this paper may be a good contribution to the development of the microgeneration sector. In what concerns the solar $P V$ potential assessment, there are several publications available all of them sharing common methodologies based on geographic information systems. The ease in implementing such GIS methodologies has strongly contributed to the identification of the available and sustainable solar $P V$ potential in cities and urbanized areas. The authors in [17] have developed a GIS methodology for the identification of suitable areas for the development of renewable energy systems. In this work the criteria established by the authors are referred to soil occupation, orientation and slope. Minimum values for the energy resource of each technology aren't used.

Other authors have developed work in this area based on GIS techniques, in different areas with several ranges of scale and with aplication to several types of renewable technologies. Examples are [18] [19] [20] [21] [22] among others.

Schallenberg-Rodriguez [23] developed a methodology for the identification of the techno-economic $P V$ potential of the Canary islands. In this work, the author has separated the building typologies namely in what concerns the type of use-residential and industrial-and the type of roof-flat or sloped, being the study referred to the rooftops only. In the present work, the approach is a little different since there is no separation between the use of the buildings and the analysis of the rooftop slope is not performed. This fact is mainly due to the lack of information on the roofs geometry and corresponding slope which led to consider that all the buildings have flat roofs in the development of this methodology. In terms of energy analysis, the assumption that all the buildings have flat roofs may lead to an underestimate of the solar resource on one hand since the optimum slopes are disregarded, but on the other hand the resource is overestimated due to shadow disregard of inclined roofs in opposite directions to sun exposure. It is then considered that there is an equilibrium in the obtained results. In the same way [23] does not consider the buildings facades since in the region where the study is referred the solar resource is reduced and has little exploitation potential. The same approach is used in the present work, although the justification is different. The urban fabric is highly variable being characterized by neighborhoods with old buildings densely distributed and where shadowed facades are expected, and also with sparsely constructed zones with open 
areas between the buildings. Also, the installation of $P V$ panels in facades of existing buildings demands complex civil construction work, being more predictable that the use of $P V$ panels in facades occurs in new buildings projected with its integration in mind. Finally, the methodology here developed intends to be practical and simple to be applied in a large range of urban regions, and the introduction of such a complex subject, as it is the study of the facades, would make it more complex and difficult to generalize.

Several studies have already been conducted in a planning perspective for the integration of renewable energy systems in urban areas where economical aspects are valued and integrated in specific models for this objective in a regional level. Some examples are the work of [24] [25]. It is important to refer that the investment costs and feed in tariffs are relatively homogeneous and stable mainly in what concerns the conventional wind energy technology which is nowadays in a high level of maturity (multi-megawatt wind turbines and conventional wind farms). The same does not happen in the microgeneration sector referred to renewable energy systems. In this case there is still a long way to go in what concerns the technology evolution until it reaches the same maturity stage. The costs of the equipment and feed-in tariffs have suffered a large drop in the recent years especially the $P V$ technology. In the Portuguese case the actual legislation has suffered several changes and the feed-in tariffs have changed every year. This way, the integration of the economic variable in the Portuguese context with such a variability of costs and tariffs would compromise the generalization and the timelessness of this methodology.

In the present case the available potential was identified by means of a GIS set of tools, developed especially for this objective. In a first phase two tools were developed, one for the identification of the wind available potential and another for the solar $P V$ available potential. To do that, the tools were programed in such a way that they can be replicated to other geometries and enable the user to change the input data according to its objectives (resource maps, input selection parameters, and other). In a second phase an interactive tool was developed for the identification of the joint potential (wind + solar $P V$ ). It is considered that this methodology brings added value and is an important contribution for the urban planning of renewable energy systems integration for several purposes in a smart cities context.

\section{Final Notes}

In this work a methodology for the identification and quantification of urban renewable potential was developed as a contribution to sustainable energy development of cities in the context of Smart Cities.

The identification of urban renewable potential was based on the mapping of energy resources obtained with Geographic information techniques and using the outputs of methodologies developed for the characterization of wind a solar potential in urban areas. To this end, interactive tools were developed in a way that enables the user to change the input data (maps of wind and solar energy 
resource) and to vary the selection parameters. It is also possible to introduce other restrictions on the installation of renewable electricity generation systems, since they can be adapted to the format accepted as input in any geographical information system platform. The developed tools allow in a first phase, the identification of wind power and solar $P V$ available as independent systems. In a second phase the identification and quantification of the wind and solar $P V$ joint potential were performed assuming that both systems can be installed together. The methodology here presented-despite the fact that it was applied to a city scale-can be applied to large-sized areas, i.e. counties or provinces.

The methods are simple and easy to apply, as desired, and constitute an asset for the energy planning of cities in a Smart Cities context by integrating wind and solar photovoltaic systems in these environments.

It is important to notice that the presented method was developed for planning purposes and, in this sense, to identify suitable places for renewable energies installation. For investment decision, more detailed studies are needed, using local measurements for a more accurate project evaluation.

\section{Acknowledgements}

The authors wish to thank the municipality of Cascais and IGOT for providing the cartography of the municipality with the buildings geometry and corresponding heights, and for enabling the use of experimental data.

\section{Conflicts of Interest}

The authors declare no conflicts of interest regarding the publication of this paper.

\section{References}

[1] Simões, T. (2004) Base de Dados do Potencial Energético do Vento em PortugalMetodologia e Desenvolvimento, Dissertação para a obtenção do grau de Mestre em ciências e engenharia da Terra. FCUL, Lisboa.

[2] Costa, P. and Estanqueiro, A. (2006) Building a Wind Atlas for Mainland Portugal Using a Weather Type Classification. Proceedings of the European Wind Energy Conference, Athens.

[3] Simões, T., Costa, P. and Estanqueiro, A. (2009) A Methodology for the Identification of the Sustainable Wind Potential. The Portuguese Case Study. Power Systems Conference and Exposition, Seattle, 15-18 March 2009. https://doi.org/10.1109/PSCE.2009.4839951

[4] Batagan, L. (2012) The Use of Intelligent Solutions in Romanian Cities. Informatica Economica, 16, 37-43.

[5] McIntyre, J., Lubitz, W. and Stiver, W. (2011) Local Wind Energy Potential for the City of Guelph. Renewable Energy, 36, 1427-1446. https://doi.org/10.1016/j.renene.2010.10.020

[6] Grassi, S., Chokani, N. and Abhari, R. (2012) Large Scale Technical and Economical Assessment of Wind Energy Potential with a GIS Tool: Case Study Iowa. Energy Policy, 45, 73-85. https://doi.org/10.1016/j.enpol.2012.01.061

[7] Simões, T., Costa, P. and Estanqueiro, A. (2009) A Methodology for the Identifica- 
tion of the Sustainable Wind Potential. The Portuguese Case Study. Proceedings of the IEEE PES Conference, Seattle, 15-18 March 2009.

https://doi.org/10.1109/PSCE.2009.4839951

[8] Dagdougui, H., Ouammi, A. and Sacile, R. (2011) A Regional Decision Support System for Onsite Renewable Hydrogen Production from Solar and Wind Energy Sources. International Journal of Hydrogen Energy, 36, 14324-14334. https://doi.org/10.1016/j.ijhydene.2011.08.050

[9] Charabi, Y. and Gastil, A. (2011) PV Suitability Analysis Using GIS-Based Spatial Fuzzy Multi-Criteria Evaluation. Renewable Energy, 36, 2554-2561. https://doi.org/10.1016/j.renene.2010.10.037

[10] Amador, J. and Domínguez, J. (2005) Application of Geographical Information Systems to Rural Electrification with Renewable Energy Sources. Renewable Energy, 30, 1897-1912. https://doi.org/10.1016/j.renene.2004.12.007

[11] Tiba, C., Candeias, A., Fraidenraich, N., Barbosa, E.D.S. and Neto, P.D.C. (2012) A GIS-Based Decision Support Tool for Renewable Energy. Renewable Energy, 35, 2921-2932. https://doi.org/10.1016/j.renene.2010.05.009

[12] Wiginton, L., Nguyen, H. and Pearce, J. (2010) Quantifying Rooftop Solar Photovoltaic Potential for Regional Renewable Energy Policy. Computers, Environment and Urban Systems, 34, 345-357. https://doi.org/10.1016/j.compenvurbsys.2010.01.001

[13] Shen, H. and Tzempelikos, A. (2013) Evaluation of Shading Retrofit Strategies for Energy Savings in Office Buildings. CISBAT13 Conference, Lausanne.

[14] Nguyen, D., Lehman, B. and Kamarthi, S. (2007) Solar Photovoltaic Array's Shadow Evaluation Using Neural Network with On-Site Measurement. IEEE Canada Electrical Power Conference, Montreal, 25-26 October 2007. https://doi.org/10.1109/EPC.2007.4520304

[15] Simões, T. and Estanqueiro, A. (2016) A New Methodology for Urban Wind Resource Assessment. Renewable Energy, 89, 598-605.

https://doi.org/10.1016/j.renene.2015.12.008

[16] C. ( ). 1.-2. ESRI (1999-2010) Model Builder.

[17] Bravo, J., Casals, X. and Pascua, I. (2007) GIS Approach to the Definition of the Capacity and Generation Ceilings of Renewable Energy Technologies. Energy Policy, 35, 4879-4892. https://doi.org/10.1016/j.enpol.2007.04.025

[18] Quijano, R.H., Botero, S.B. and Dominguez, J.B. (2012) MODERGIS Application: Integrated Simulation Platform to Promote and Develop Renewable Sustainable Energy Plans, Colombian Case Study. Renewable and Sustainable Energy Reviews, 16, 5176-5187. https://doi.org/10.1016/j.rser.2012.05.006

[19] Rylatt, M., Gadsen, S. and Lomas, K. (2001) GIS-Based Decision Support for Solar Energy Planning in Urban Environments. Computers, Environment and Urban Systems, 25, 579-603. https://doi.org/10.1016/S0198-9715(00)00032-6

[20] Gadsen, S., Rylatt, M. and Lomas, K. (2003) Putting Solar Energy on the Urban Map: A New GIS-Based Approach for Dwellings. Solar Energy, 74, 397-407. https://doi.org/10.1016/S0038-092X(03)00190-7

[21] Strzalka, A., Alam, N., Duminil, E., Coors, V. and Eicker, U. (2012) Large Scale Integration of Photovoltaics in Cities. Applied Energy, 93, 413-421. https://doi.org/10.1016/j.apenergy.2011.12.033

[22] Izquierdo, S., Rodrigues, M. and Fueyo, N. (2008) A Method for Estimating the Geographical Distribution of the Available Roof Surface Area for Large-Scale Pho- 
tovoltaic Energy-Potential Evaluations. Solar Energy, 82, 929-939.

https://doi.org/10.1016/j.solener.2008.03.007

[23] Schallenberg-Rodríguez, J. (2013) Photovoltaic Techno-Economical Potential on Roofs in Regions and Islands: The Case of the Canary Islands. Methodological Review and Methodology Proposal. Renewable and Sustainable Energy Reviews, 20, 219-239. https://doi.org/10.1016/j.rser.2012.11.078

[24] Ramachandra, T.V. (2009) RIEP: Regional Integrated Energy Plan. Renewable and Sustainable Energy Reviews, 13, 285-317. https://doi.org/10.1016/j.rser.2007.10.004

[25] Tsoutos, T., Drandaki, M., Frantzeskaki, N., Iosifidis, E. and Kiosses, I. (2009) Sustainable Energy Planning by Using Multi-Criteria Analysis Application in the Island of Crete. Energy Policy, 37, 1587-1600. https://doi.org/10.1016/j.enpol.2008.12.011 